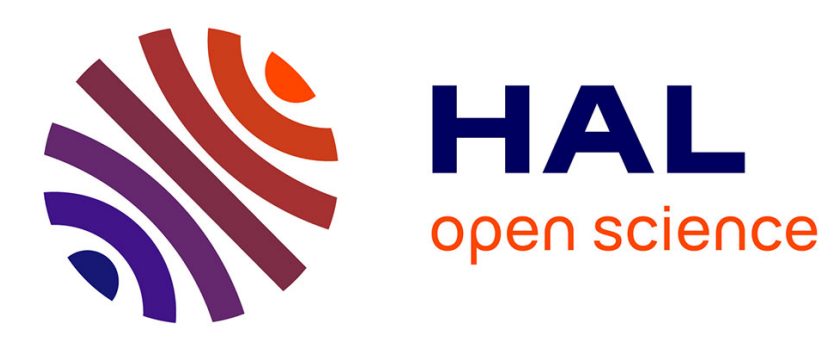

\title{
Une approche psychothérapeutique des phénomènes psychosomatiques et de la corporéité à l'île de La Réunion
}

I Rassaby-Darsanesing, A Bioy, J-C Lavaud

\section{- To cite this version:}

I Rassaby-Darsanesing, A Bioy, J-C Lavaud. Une approche psychothérapeutique des phénomènes psychosomatiques et de la corporéité à l'Île de La Réunion. Psychologie Clinique, 2016. hal-01470595

\section{HAL Id: hal-01470595 \\ https://hal.science/hal-01470595}

Submitted on 17 Feb 2017

HAL is a multi-disciplinary open access archive for the deposit and dissemination of scientific research documents, whether they are published or not. The documents may come from teaching and research institutions in France or abroad, or from public or private research centers.
L'archive ouverte pluridisciplinaire HAL, est destinée au dépôt et à la diffusion de documents scientifiques de niveau recherche, publiés ou non, émanant des établissements d'enseignement et de recherche français ou étrangers, des laboratoires publics ou privés. 


\title{
Une approche psychothérapeutique des phénomènes psychosomatiques et de la corporéité à l'Île de La Réunion.
}

I. Rassaby-Darsanesing*, A. Bioy**, J-C. Lavaud***

*Psychologue clinicienne, Etablissement Public de Santé Mentale de La Réunion - Doctorante en Psychologie, Université de Bourgogne Franche-Comté, Laboratoire PSY-DREPI.

**Professeur de psychologie clinique et psychopathologie, psychologue clinicien, Laboratoire PSY-DREPI, Université de Bourgogne Franche-Comté.

*** Docteur en Anthropologie Sociale et Ethnologie de l'EHESS-Paris - HDR, chercheur associé au Laboratoire PSY-DREPI, Université de Bourgogne Franche-Comté - Psychothérapeute-Hypnothérapeute, 11 Canabady II ; Saint-Pierre.

\section{Résumé}

Les fondements culturels, les croyances et les pratiques rituelles qui y sont associées, définissent de façon particulière le rapport au corps, des représentations et des vécus psychiques liés au corps. C'est à travers le langage que nous pouvons investiguer la spécificité culturelle de ces contenus mentaux, intimes ou partagés, et travailler avec eux. Cet article expose les croyances liées au corps dans la religion d'origine d'un patient réunionnais puis interroge le rôle de la dimension culturelle des phénomènes psychosomatiques. L'étude de cas développée ici ouvre sur une approche thérapeutique originale de cette problématique et met en avant le lien intrinsèque entre appartenance culturelle et corporéité.

Mots clés : corporéité - psychosomatique - langage - culture - Ile de la Réunion

\section{A psychotherapeutic approach of psychosomatic phenomena and embodiment in Reunion Island}

\begin{abstract}
The cultural foundations, the beliefs and rites of a society influence the way an individual embodies psychological perceptions and psychical experiences of the body. Language enable the investigation of cultural linguistic specificities, deciphering and working-through of related commonly held beliefs or personal meanings of these mental contents. This article first exposes the common beliefs about the human body in a reunionnese patient's original religion. It examines then the role of the patient's cultural background in psychosomatic
\end{abstract}


manifestations in Reunion Island. The work on this case study develops an original psychotherapeutic approach for this dimension.

Keywords : embodiment - psychosomatic - language - culture - Reunion Island

\section{Introduction}

L'île de La Réunion s'est bâtie sur un socle éminemment multi-culturel. Le métissage identitaire reste particulièrement actif dans les représentations de soi, du corps, du monde, de la vie et de la mort, avec un dialogue constant entre culture partagée collectivement, croyances individuelles, et remaniements propres au vécu corporels.

La culture réunionnaise est mue par un système de croyances aux origines multiples, qui infiltre différents secteurs de la vie dont celui du corps et de la santé. Par exemple, il apparaît que le corps, investi par des entités ancestrales ou démoniaques si les rituels ne sont pas observés, devient alors l'objet d'autres entités que le sujet lui-même. Notre pratique clinique d'une dizaine d'années nous a montré que c'est notamment le cas dans les maladies chroniques (douleurs, diabète...), les maladies dégénératives et les douleurs liées aux organes.

Cependant, aujourd'hui, le savoir et les représentations ancestrales, l'essentiel de l'héritage culturel, semblent s'effacer peu à peu face à l'influence toujours plus importante de la Médecine occidentale (dont la Psychiatrie). Les choix de registres de soin sont multiples, révélateurs de la gamme des vécus corporels, des corporéités, mais révélateurs aussi de la diachronie et de la synchronie des représentations. Pour autant, la construction identitaire réunionnaise continue à rythmer la vie du peuple réunionnais ; les événements religieux étant légions et rythmant l'année, les pratiques en lien avec les croyances sont admises par tous (mais pas pour autant observées par tous), et une visibilité des pratiques traditionnelles est toujours présente. Héritier de toutes ces influences, le parler réunionnais, le créole, dans sa structure et ses non-dits, sa syntaxe et ses néologismes, est empreint de toute cette diversité, de ces expériences et de ce parcours identitaire encore à l'œuvre. 
Dans ce contexte, nous souhaitons illustrer cliniquement ces dimensions dans le but de dégager quelques pistes de réflexion sur la prise en charge de la composante culturelle en consultation psychologique.

Les travaux en Psychologie, en Ethnopsychiatrie et en Anthropologie sur la psychosomatique et la transculturalité ont interrogé les spécificités dans le rapport au corps en fonction de notre culture.

\section{L'héritage transgénérationnel d'un rapport à soi et au monde particulier :}

Ce métissage culturel s'est avant tout construit à partir des cultures d'origine des migrants, de leur religion, mais aussi du mode de relation (juridiquement et socialement prescrit) entre les hommes.

Bien que bon nombre de cultures très variées soient fondatrices du peuple réunionnais, ${ }^{1}$ il est important de rappeler que les règles appliquées lors de l'importation ${ }^{2}$ des esclaves sur cette terre vierge ont limité l'expression, la perpétuation et la transmission de la plupart d'entre elles. Par ailleurs, la mission évangéliste des colons poussa une grande partie des migrants, pour devenir une personne 'respectable' dans une société catholique, à renier leur appartenance religieuse et les sous-bassements culturels qui y sont associés. ${ }^{3}$

Enfin, les conséquences traumatiques de la traite esclavagiste (en résonance constante à travers les évènements contemporains) ajoutent au tableau plurifactoriel de l'héritage identitaire du réunionnais.

Ainsi, Pourchez (2005) écrit que la mixité culturelle à La Réunion est surtout basée sur l'héritage des communautés européenne, malgache et indienne. Nous allons pour notre part nous concentrer sur les représentations et cultes issus de l'héritage indien, en lien avec le cas clinique que nous développerons. Notons néanmoins que c'est à la croisée des traditions indiennes et malgaches, essentiellement, que tout le symbolisme de la culture réunionnaise a

\footnotetext{
${ }^{1}$ Citons les captifs d'Afrique de l'Est, les Malais, les Polynésiens, les Aborigènes australiens, les Chinois... (Pourchez, 2005)

2 Ex : règle de la séparation des esclaves de mêmes origines et de mélange des ethnies liées par la rivalité, permettant de maintenir l'homéostasie du système de domination (impossibilité d'organiser une mutinerie, nécessitant un minimum d'alliance).

${ }^{3}$ La renomination des affranchis (affranchissement administratif, car les anciens esclaves étaient encore possédés symboliquement par le fait qu'ils se voyaient très souvent attribuer comme nom de famille le prénom de leur ancien maître, ou celui d'un personnage de la mythologie grecque) a achevé la rupture avec les origines et rompu le sentiment identitaire.
} 
trouvé une identité propre. C'est ainsi qu'on observe, dans les cours privées, au bord des routes ou dans le creux d'une falaise, des petits autels dédiés aux divinités reconnues par chacun, invoquées dans les prières et les rituels. La religion à La Réunion existe partout et par tous.

Dans ce pluralisme culturel, on peut dégager des principes de base qui créent une certaine cohérence structurelle de la culture réunionnaise. Par exemple, le corps y est considéré comme un substrat matériel et tangible par lequel s'opèrent les échanges entre les mondes profane et sacré. Ce corps est donc fragile, car soumis à des potentielles attaques d'esprits malveillants. Il est d'ailleurs utile de poser une distinction lexicale fondamentale dans la conception créole : nous parlerons ici d'âme pour désigner la psychè, car « esprit » renvoie, dans la culture réunionnaise («zespri » ou «bébèt »), à une entité autre, créant des désordres somatiques ou mentaux chez celui qu'il va investir. Le mens sana in corpore sano agit fortement dans la culture créole, qui y ajoute un antecessor contentus (ancêtre satisfait).

C'est ainsi que les rituels visent le maintien de l'unité somato-psychique avant même la conception de l'enfant, accompagnent la grossesse et le développement in utero, la naissance et les passages identifiés comme cruciaux dans la vie et la mort, en fonction des cultures (Govindama, 2011, Grandidier, 1932). De façon globale, ces spécificités opèrent donc sur les différents niveaux de la vie psychique et pré-psychique de l'individu. Dans le même mouvement, la symbolique cultuelle vient rappeler le lien au mythe fondateur, lié à la divinité qui régit la famille, agissant comme point d'ancrage de l'affiliation et du respect des générations. Ainsi, le corps de l'enfant à naître est différencié du corps de sa mère, est institué dans la lignée des générations. Le rituel permet une incarnation de l'âme (immortelle) et le fœetus est alors reconnu comme mortel.

L'ethnologue Tarabout (2012), requestionnant la notion d'ancestralité, rappelle cependant que la croyance en la réincarnation n'est pas commune à tous les hindous : il existe « une variation des conceptions de la personne, de la mort, du devenir des défunts et de l'ancestralité », en fonction des régions et de l'appartenance à une caste. Le clinicien doit tenir compte du déterminisme en termes d'identité que le postulat de la réincarnation implique. Quoiqu'il en soit, dans l'univers hindou, la filiation est uniquement paternelle, ce qui marque fondamentalement (nous le verrons dans notre cas clinique) un déterminisme du vécu identitaire. 
Nous pouvons déjà identifier une particularité dans les représentations de soi (en tant qu'unité rassemblant un corps et une âme) : les rituels hindous, passant par le corps, visent l'intégrité de l'âme, qui préexiste au corps et lui subsistera après la mort : la vie terrestre n'est qu'un passage, lors duquel l'âme va évoluer et s'affranchir petit à petit des intérêts terrestres (l'apogée étant le brahmanisme, Tarabout, 2012). L'imaginaire collectif hindouïste, bien qu'ancré dans un dualisme, se différencie ainsi de celui que l'on attribue à Descartes.

Pourchez (2004) apporte une analyse pluriculturelle des représentations de l'embryogénèse chez les réunionnais: les représentations sont très diverses, du fait de la mixité mais également du processus d'acculturation («au sens de réinterprétation des données exogènes » précise-t-elle). Ainsi, on peut observer que, chez certaines mères, l'embryon ne peut être considéré comme enfant qu'après un temps de latence, qui correspond au délai nécessaire pour une éventuelle méthode abortive. Ces observations varient, en fonction de la culture à laquelle les parents s'identifient, mais également de leur âge (qui sous-tend une certaine ignorance ou au contraire une sensibilisation aux données scientifiques sur l'embryogénèse). Nous pouvons néanmoins les relier à la perception de la conception chez les Malgaches (et d'autres ethnies africaines), selon laquelle deux rapports sexuels distincts sont nécessaires pour officialiser l'existence physique et spirituelle de l'embryon.

Dans la conception hindoue, le sperme du père apporte les os, la chair et le sang, qui consolidés dans l'utérus de la mère formeront le futur bébé, l'âme s'invitant dans le corps à la rencontre des gamètes de l'un et l'autre. Si cette vision est forte en symbolismes, elle peut évoquer la définition aristotélicienne de l'âme, âme sans laquelle le corps ne serait pas corps.

Par la suite, des rituels sont prescrits tout au long de la grossesse, alliés à des prescriptions et interdits alimentaires, ayant pour objectif de non seulement garantir la poursuite du développement de l'embryon/ fœetus, mais également de protéger l'enfant de «l'ambivalence des sentiments maternels » dont les fantasmes d'infanticide (Govindama, 2002) et d'assigner une place au père. Nous apercevons déjà ici la fonction régulatrice des rôles sociaux dans les rituels.

Le métissage et les apports occidentaux sur la perception de soi-même et du monde ont fortement contribué à une certaine dilution voire une déperdition des pratiques rituelles. On assiste alors à des positionnements et des mouvements contraires vis-à-vis de la question 
identitaire $^{4}$ : entre modernisation et revendication, le réunionnais tente constamment de se définir en tant que personne, individu et sujet.

Tous ces données rejoignent les théories anthropologiques sur la notion de personne, en ce qu'elle émane essentiellement de composantes matérielles (physiques) et immatérielles (spirituelles). Cette définition rappelle l'éternel dualisme corps/esprit, le tout étant l'héritier de l'histoire de la famille, de la société et de la culture. S'il est aisé de se définir socialement par son nom, son statut, sa lignée, sa religion, le discours sur le corps est peu habituel, alors même qu'il transparaît dans la langue. Interroger l'existence du corps dans le créole nous permettra de mieux saisir la perception de l'expérience intime du sujet en tant que tel.

\section{La représentation du corps à travers le langage créole}

Le créole est issu d'un métissage des cultures : la langue (écrite ou orale) constitue à la fois une trace et une perpétuation d'une histoire et d'un rapport au monde. ${ }^{5} \mathrm{Ce}$ 'parlé' réunionnais, est marqué par la prédominance des métaphores de la Nature (faune et flore). Il est alors le vecteur d'une corporéité singulière : Comment le créole met en scène le corps ? Comment le désigne t-il ? Contient-il des acceptions particulières en ce qui concerne le corps ? Comment la culture créole, à travers les dictons et proverbes, fait-elle vivre le corps ?

La partie du corps citée est, dans la syntaxe créole, dissociée du reste du corps, prenant alors la place d'une entité distincte : «mon tèt' i fé mal », «ma la casse mon jamb », «la tèt' la pas bon », «nou la fé pèt' nout' vent' », «larg' pa lo kor » (ne pas se relâcher dans l'effort). ${ }^{6}$ Le français littéraire, où cette formulation est impropre, impose la forme pronominale subjective (je me suis cassé la jambe $\neq$ j'ai cassé ma jambe), qui suppose une relation, une unité du corps, une identification du membre/organe au corps auquel il est rattaché.

Les parties du corps humain sont souvent nommées à partir de mots réservés aux animaux : «le zhabo»= le jabot (oiseau), «le kolé»= le collet (volaille), «la patte» pour dire familièrement la jambe, «le nazo »= le naseau (bovin),... Il est courant d'entendre «femèl » (=femelle) pour dire «la femme» et « «mâl » pour dire «l'homme», bien que cela puisse

\footnotetext{
${ }^{4}$ Jean-Luc BONNIOL développe brillamment cette idée dans Paradoxes du métissage (2001).

${ }^{5}$ Daniel HONORE a d'ailleurs intitulé un de ses recueils «Diktionnèr mo-fék-nèt » : « les mots ne font que naître », ce qui renvoie non seulement à l'importance du néologisme dans le lexique créole, mais également à une construction diachronique, en constante évolution de cette langue.

6 À savoir que l'expression «larg' lo kor » peut signifier « abandonner, renoncer », mais aussi «s'évanouïr, défaillir ».
} 
avoir une connotation péjorative (à laquelle on ajoute le nom d'un animal pour former des insulte : «femèl le chien »), ou au contraire contenir une notion d'affection (« un mâl matou» = un chéri, un amant).

La plupart des dictons/proverbes créoles ne font pas apparaître le corps humain mais l'animal, les plantes, les matériaux, comme par exemple :

- «zoreil cochon dann' marmite pois »= les oreilles du cochon dans la marmite de pois [n'entendent rien], ou «do lo su fèy songe »= l'eau sur la feuille de songe [glisse, ne s'accroche pas]. Ces deux expressions renvoient à la nécessité de ne pas s'accrocher à des commentaires, des critiques, ou des évènements sur lesquels nous n'avons pas prise ou qui ne sont pas si importants.

- «bèf mor, i lès la mizèr pou son po »= lorsqu'un pauvre bougre meurt, la misère à laquelle il met fin s'attaque à sa femme et ses enfants (Honoré, 2002).

- «margoz lé amer, mais lo grin lé dou»: l'équivalent de «l'habit ne fait pas le moine» (le margoz est un légume, amer, dont les graines sont sucrées)

Dans les dictons/proverbes où le corps humain est mis en scène, il est souvent question de violences, ex : "zenfan y yem som' le kèr, y dresse som' la main » (= on aime un enfant avec le cœur, on l'éduque avec la main)/ «cet' y donn' chabouk y rale pas charett» (= qui donne du fouet ne tire pas la charrette). «Change la chair » signifie changer de partenaire en amour. La trivialité, le caractère presque boucher, du corps dans l'acte sexuel y est stupéfiant.

Parfois, il existe des déplacements anatomiques dans le langage créole : par exemple, «le lestoma » (l'estomac) désigne chez le créole la poitrine, c'est-à-dire la partie thoracique supérieure, contenant certes l'estomac mais aussi le cœur. Par extension, dans le langage populaire, l'estomac désigne finalement le cœur, comme dans l'expression «mon lestoma i batt' kart'», qui signifie littéralement, «mon estomac bat les cartes, figurant dans le mouvement, le son et le rythme du battage des cartes à jouer, la tonitruance du cœur lorsque l'on a peur. Cette expression signifie donc «j'ai peur ».

Bien que nous puissions observer des inversions similaires en français («avoir le cœur au bord des lèvres », « avoir des haut-le-cœur »), nous avons ici un aperçu de la richesse symbolique, allégorique du langage créole qui finit par prendre une place de réalité dans les représentations du corps interne chez le créole. 
Ces glissements, condensations, confusions sémantiques ne sont pas sans conséquences du point de vue de l'ancrage psychosomatique. Citons cette dame, marquée par le silence du deuil de son petit garçon, il y a de cela plus de 30 ans. Cette patiente présente, au premier plan de sa demande de prise en charge psychologique, de multiples pathologies éparses, traitées localement par le médecin traitant et les spécialistes. Entre autre, cette dame souffre de reflux gastro-œsophagien avec brûlures gastriques. Lors de notre première rencontre, nous abordons les conséquences à long terme du deuil traumatique dans toute la famille. Nous lui proposons, à la rencontre entre la psychosomatique et la systémie, l'image de la crypte : «c'est comme si toute la famille vivait depuis lors avec un cercueil juste là?», interrogeons-nous. Le «là» appuyé d'une main sur notre plexus solaire, point de rencontre du cœur et de l'estomac. A ce moment, la patiente fond en larmes, libère la lourde peine qu'elle (et sa famille) a contenue depuis le jour du décès et nous répond : «Vous savez, en créole, on dit 'mon cœur i saigne'. Eh bien, Madame, mon cœur i saigne ».

\section{Situation clinique :}

Nous souhaitons à présent proposer une illustration clinique afin de questionner la façon dont ces données culturelles résonnent dans un cadre de consultation psychologique (Centre médico-Psychologique) sur l'île de La Réunion.

Monsieur est connu du CMP depuis de nombreuses années lorsque le psychomotricien nous l'oriente en psychothérapie. Ce dernier explique que Monsieur est invalidé, depuis fort longtemps, par des troubles physiques multiples et variés, sans étiologie médicale connue. Ainsi, le patient a dû quitter son poste de travail et a pu être « reclassé » dans des fonctions qui le mettent moins à mal.

Le patient présente en effet un trouble vocal particulièrement prononcé, comme si sa voix se dérobait, rendant l'adresse à l'autre très compliquée. Il explique d'emblée que ce qui lui pose problème aussi, c'est que «mon corps me joue des tours ». Intriguée, nous l'interrogeons : "parfois, lorsque je me décide à faire quelque chose, je marche pour aller le faire et je me fais un cale-pied... enfin, mon pied me le fait, et je tombe. D'autre fois, je me mords la langue, l'intérieur des joues ou des lèvres, sans le vouloir et sans m'en rendre compte. Jusqu'au sang. Je veux attraper un objet et ma main le fait tomber. Ça devient compliqué de négocier avec ce corps qui refuse catégoriquement de m'écouter. » Bien que Monsieur rit 
souvent en faisant le récit des péripéties avec son corps, l'agacement et l'angoisse se font constamment sentir. Il conclut en disant : «mon corps est mon ennemi. »

Nous investiguons avec lui l'origine des troubles : pour Monsieur, tout est clair. Un jour, alors qu'il allait entamer sa journée de travail, récompense de nombreuses années d'études universitaires et de concours, il a été pris d'une soudaine angoisse, si intense qu'il n'a pas pu s'y engager. "C'est comme si je comprenais soudain que je ne devais pas être là, comme si s'imposait à moi l'idée que je me mentais totalement en faisant ça. »

Il est à noter que le père de Monsieur était un Pûsari ${ }^{7}$, reconnu comme puissant par la communauté locale. Il était dur et froid, distant, puis a connu une forte dépression qui le plongea dans un alcoolisme sévère. Il n'est pas aisé pour Monsieur de parler de son père, dont il n'a comme souvenir qu'il «était là, dans le canapé et on ignorait souvent s'il était vivant ou mort. On ne faisait plus attention à sa présence si bien qu'il n'existait même plus. » Ce père faisait partie de la pièce, comme le canapé duquel il ne se levait pas.

La mère est décrite comme une mère aimante, affectueuse, omniprésente, mais à double visage, car cette mère si joyeuse et extravertie devenait soudainement éteinte, presque prostrée, angoissée et peureuse, dès lors qu'elle passait le seuil de la maison pour aller à l'extérieur. C'est d'ailleurs à ces moments que se fixe l'image mémorielle de la mère : «dès que l'on sortait de la maison, je lui tenais le bas de sa jupe, comme un objet transitionnel qui me protégeait des autres. »

Les doubles préexistaient à l'enfant que Monsieur était. Le visage de l'intérieur et le visage que l'on donne à voir entrent en écho avec la dualité corps/esprit. Si le patient intellectualise souvent en séance sur ce sujet, il lui semble impossible de trouver une troisième voie/voix à être : à l'intérieur une mère joviale et un père presque mort, à l'extérieur une mère effrayée et un père puissant. Monsieur évoque la dualité cartésienne, à travers les idées de confrontation, d'opposition et de contradiction. Lorsque nous lui proposons la notion de paradoxe, il a été capable d'opérer une véritable conciliation de sa pensée sur lui-même.

Il décrit une relation particulièrement fusionnelle à la mère, qui réapparaît plus tard dans un «sentiment d'illégitimité » et la sensation d'être «là à la place d'un autre »: si l'on peut avoir une lecture simplement œdipienne de cette phrase, on peut aussi avancer l'impossibilité

\footnotetext{
${ }^{7}$ «Pûsari » signifie « le maître des rituels ». Le réunionnais l'appelle «prêtre malbar », comme il nomme le «prêtre malgache ».
} 
pour Monsieur de s'envisager, culturellement, dans le cycle des réincarnations, de son ancrage dans la lignée. Les deux visions se rejoignent dans la perspective culturelle hindoue, puisque la filiation ne se fait que par la lignée paternelle.

Monsieur rapporte des souvenirs de lui enfant à l'image de ceux de sa mère, dont il a pu peu auparavant identifier les projections émotionnelles sur lui. «Dans la maison, j'étais un vrai feu-follet. D'ailleurs, ma mère se plaignait de moi car je ne tenais pas en place. Dès que je passais la porte de la maison, je ne sentais plus mon corps. C'est comme si mon corps n'existait pas. » Monsieur partage le souvenir, récemment ressurgi, de violences dont il a été victime dans la cour de l'école, par un nommé « Octave » (ce fut bien évidemment l'occasion de questionner le patient sur l'écho dans son symptôme vocal). «Etrangement, même s'il me faisait souvent des crasses, comme des cale-pieds ou des coups de poing quand il passait à côté de moi, je l'aimais bien, Octave. Je l'admirais. Il était tout ce que je n'étais pas capable d'être. J'admirais qu'il se permette d'exprimer avec autant de conviction toute la violence qui l'habitait. Et puis, lorsqu'il me frappait, j'existais, en dehors de la maison. » Nous lui proposons l'hypothèse que les «tours » que lui jouent son corps au moment où il se met en action évoquent une incorporation de cet Octave.

Monsieur dit, un jour, qu'il ne connaît aucune forme de plaisir corporel, qu'il ne comprend pas même les besoins sexuels de sa femme auxquels il a du mal à répondre. Il exprime davantage d'aisance à répondre «par le corporel que par le génital » aux demandes d'amour de son épouse, «le corporel» signifiant pour lui la tendresse et l'affection non sexuelle. Il explique que la lecture de Spinoza a «tout fait basculer dans ma vie. C'est là que je me suis dit : 'C'est ça que tu dois être' », à savoir un ascète, effacé, transparent. A aucun moment, Monsieur ne se rend-il compte qu'il opère un rapprochement progressif du brahmanisme!

«Son ascèse n'est pas une contrainte, encore moins une nuisance, elle est une activité appréciée des dieux, qu'ils récompensent en octroyant leur grâce. », écrit Tarabout (2005).

\section{La place de la psychosomatique dans la psychothérapie :}

Keller (2006) insiste sur la difficulté intrinsèque de l'être humain à se concevoir dans une unicité regroupant le corps et la psychè. Il introduit, dans Le dialogue du corps et de l'esprit, la nécessité de prendre en considération le discours incessant que le sujet produit à propos ou 
à destination de son corps et celui, bien plus complexe et inintelligible pour soi-même, que son corps lui adresse.

Il soutient que «l'objet-corps n'a d'existence pour l'être humain que marqué d'un sceau culturel, chaque culture ayant à charge d'en donner sa propre définition » (p.58)

Dans le cas de Monsieur, l'essentiel de la psychothérapie a consisté à l'amener à reconnaître que le «combat» que lui imposait son corps était un reflet de ce contre quoi il luttait férocement : son histoire, ses origines, sa lignée, sa culture, sa religion, son statut d'homme et d'homme lettré et brillant, ... en bref, Monsieur était en lutte contre lui-même, ne semblant pas trouver de satisfaction de lui-même. Cependant prompt à se raconter, riche d'une élaboration et d'associations psychiques fortes, il lui était impossible de rattacher le tout de lui-même, puisque rien ne lui convenait. C'est ainsi que son corps tenta de dénoncer auprès de lui, l'inanité de ce combat et l'insensé dans cette entreprise. Il lui joua donc des tours...

Ce qu'il ne dit pas mais qui est à voir fait l'objet de notre attention de clinicienne : son corps, posé sur la chaise basse du bureau, reste rigide, tel un bout de bois («ti paquet d'bois/d'riz » pour parler de l'enfant que l'on balade, que l'on pose là). Par ailleurs, il est parfois pris de salves de tremblements, sur lesquels il ne verbalise pas, à tel point que nous questionnons même la conscience de leur existence. Ces manifestations corporelles rappellent le « sèzisman » (saisissement), qui à la Réunion peut être la preuve de l'effroi traumatique ou témoigner de la transe lors des rituels, ${ }^{8}$ transe apparaissant lorsqu'un ancêtre s'empare du corps du dévot et se met à «parler langaz » (parler le langage, des ancêtres).

Le rôle du fantasme dans la somatisation est prégnant (Bronstein, 2016). Donabédian (2016) explique que, dans les rêves des patients «psychosomatiques », «si le fantasme est clairement identifié par le moi, la défense maximale sera une répression farouche entravant toute vie libidinale objectale et narcissique du sujet. » (p.23)

Le travail sur l'activité onirique intense et particulièrement riche symboliquement permet à Monsieur de se réapproprier ce qu'il avait refoulé de lui-même. Ainsi, il rapporte un rêve où un père coupe le cou d'un poulet. Il questionne de lui-même : «qui est ce père ? Qui est ce poulet? » Le lien verbalisé avec lui aux rituels sacrificiels tamouls lui permettent de reparler des quelques fois où il a assisté aux «services» présidés par son père. «Je n’aimais pas

\footnotetext{
${ }^{8}$ Cette transe s'observe tant lors des rituels tamouls que malgaches, voire même lors de certaines messes catholiques (Messe des Malades, à l'Eglise du Chaudron - quartier de St Denis de la Réunion).
} 
ça. C'est inhumain. » Il évoque «l'hystérie collective, toute cette mascarade pour chercher à s'éloigner de ses propres responsabilités dans ce qui nous arrive. » Le travail sur ce rêve permet d'initier une conciliation avec le symptôme vocal. Il fait part de ses questionnements sur la question de la «menace, l'épée de Damoclès». Il dit alors que lorsque sa voix s'éteint, il a l'impression d'avoir un «objet métallique au travers de la gorge que je n'ai pas d'autre choix que d'avaler ». Pour lui, «métallique ${ }^{9} »$ signifie «froid, inhumain ». Cette potentialité dans l'élaboration marque un tournant dans la psychothérapie: à partir de ce moment, Monsieur peut approcher la question de sa propre image, de sa personne, de sa corporalité (« corps oralité » disait le psychomotricien de Monsieur).

Smadja (2014) rappelle que «l'un des caractères les plus surprenants de la somatisation [...] est le caractère de projection de la somatisation » (p.17). Le lien fait entre ces qualificatifs et ceux que Monsieur utilise pour décrire son père et les rituels qu'il pratiquait lui donne la possibilité de relier le symptôme des morsures à son incapacité à pacifier les difficultés familiales et notamment le rapport «brutal» entre son épouse et ses enfants (il n'y a pas de violences à proprement parler mais une distance affective que Monsieur a du mal à accepter de la part de la mère de ses enfants).

La boucle est bouclée : la réflexion sur la transmission à ses propres enfants de ce qu'il a reçu peut s'engager. Au terme de deux années intensives d'entretiens quasi hebdomadaires, nous en arrivons ensemble à la conclusion qu'il existait un conflit acharné et perpétuel avec ses origines, à tout point de vue : être le fils de son père lui était tellement inconcevable que celuici n'apparaissait jamais spontanément dans le discours de Monsieur, être l'enfant d'une famille «médiocre » socialement ne lui convenait pas non plus après sa réussite professionnelle et familiale, enfin, être un malbar était au-dessus de l'imaginable pour lui : «vous savez, un malbar avec cabri au fond de lui cour, moustache et dents en or,... tout ce que je ne supporte pas. » Tout ceci résonne fortement avec la parole sur ses expériences corporelles : «mon corps est mon ennemi. » Rappelons la conception clivée de la part des gamètes mâle et femelle dans la formation de l'embryon. L'incarnation impossible renvoie fortement aux difficultés identificatoires chez ce patient. En effet, dans le discours du patient apparaissent des imagos parentales tellement figées qu'elles évoquent à plusieurs égards les complexes parentaux jungiens, si puissants qu'ils ne laissent que peu de place à l'enfant d'exister, physiquement comme psychiquement, en dehors de leur présence, regard, geste.

\footnotetext{
${ }^{9}$ A noter qu'en créole, « un métallique » réfère au grillage qui sert à la séparation entre les terrains.
} 
Monsieur en fait sa définition propre: «les mauvais parents, ceux qui ne considèrent pas la parole de l'enfant, qui exigent beaucoup de lui mais ne donnent rien, de qui on ne peut rien retirer ». Libéré du joug de la «grande-mère » (selon l'expression de Jung), Monsieur peut faire de la place à son père et s'envisager en tant que tel pour ses enfants (sans courir le risque d'être un «mauvais parent »), qu'époux auprès de sa femme, qu'homme au sein de la société.

Le diagnostic psychiatrique posé initialement pour Monsieur faisait référence à un «trouble dissociatif de conversion/troubles névrotiques anxieux et phobiques ». Suite à la psychothérapie, le psychiatre constate une amélioration du tableau clinique général, notamment du trouble phonique et des troubles anxieux, et la disparition des éléments dépressifs et des obsessions. Les traitements ont été diminués jusqu’à leur arrêt total.

De notre place de psychologue, il fut plus qu'utile, face à Monsieur qui employait presque exclusivement le français, de réintroduire la nécessité de se relier ${ }^{10}$. Il s'est donc agi de proposer des mots, des expressions, des dictons et proverbes pour parler du corps et de ses manifestations, les interroger et leur donner à leur tour la parole. Le dialogue, au sens de Keller, est rendu possible. Parallèlement, la langue créole, avec sa puissance symbolique, permit des renvois subtils aux origines, à la culture, à l'identité, et au final, au nondéterminisme que son éternelle construction rappelle. On pourrait dire, en ce sens, que le créole est finalement la langue de la libération psychique: elle remémore l'histoire des ancêtres, l'héritage commun, mais également l'ouverture vers un avenir propre à soi. Après un travail de pacification du vécu infantile massif, de remaniement des figures parentales, dans la double perspective psychologique et culturelle, Monsieur a alors pu consentir à se resituer, parvient à assumer son histoire et ce qu'il avait oublié de ses protagonistes

Le psychologue est appelé à modifier son positionnement. Il est question de donner un sens au dialogue corps/psychè dans le tissu des représentations culturelles et le maillage identitaire, qui dépassent le patient et le clinicien lui-même. Parler son langage, sa langue et s'appuyer sur son schéma (ici insu ou volontairement ignoré par Monsieur) d'inscription culturelle à la réalité. Cela nécessite un effort d'apprentissage, de découverte et d'ouverture sur le monde interne de l'autre et de sa communauté religieuse.

\footnotetext{
${ }^{10} \mathrm{Au}$ sens de religere, religio, étymologie de religion.
} 


\section{Conclusion :}

Sont à l'œuvre les échos contemporains des stigmates identitaires hérités dans le discours des sujets et la souffrance qui y est associée: le clivage imposé jadis agit encore, parfois insidieusement, et ouvre la voie à un eugénisme culturel. En ce sens, la réalité des réunionnais pourrait rejoindre celle de toute culture où s'est exercée, à un moment de son histoire, un rapport de domination marqué par la violence.

Néanmoins, le peuple réunionnais a cette particularité d'avoir à la fois perdu et innové, renouvelé sa culture, son rapport au monde et le rapport à soi. Pour tenter d'apporter une vision holistique de la question du «sentiment identitaire », nous pourrions citer Ghasarian (2002), qui met en avant les reformulations incessantes (allant de tentatives de syncrétismes culturels à la revendication de la pureté de la culture d'origine) à l'œuvre dans la société réunionnaise :

Si l'acculturation suppose la mise en présence d'au moins deux systèmes et modèles culturels dont l'un s'impose à l'autre, la créolisation suggère au contraire un mélange de modèles culturels aboutissant à un compromis de ceux-ci dans une nouvelle forme plus ou moins syncrétique. La réinvention culturelle manipule quant à elle les modèles imposés et ceux nés du contact forcé pour produire, souvent explicitement, de nouvelles significations sociales. ${ }^{11}$

Nous pouvons lire, dans ces essais, ces allers-retours d'un pôle à l'autre du mouvement identitaire, la confrontation entre la tentative d'oubli de l'histoire (douloureuse, floue, niée) et la quête perpétuelle des origines, universelle et intemporelle. Ces stratégies de guérison semblent inefficaces, se répétant et s'enchaînant, s'annulant et ressurgissant.

La question du corps reste profondément attachée à l'histoire du peuple, de la famille de laquelle le réunionnais naît, de ses croyances, de ses pratiques, de son positionnement par rapport à son héritage. Il apparaît évident que Monsieur a terriblement souffert de la rupture à ses origines, rupture qui lui a été nécessaire pour tenter d'émerger au monde en tant que sujet propre, de se débarrasser des traumatismes, des dettes, des rites et mythes familiaux, œuvrant à son insu et au grand dam de son corps.

\footnotetext{
${ }^{11}$ C. Ghasarian. 2002 p.663.
} 
Nous faisons la proposition de développer une approche psychosomatique transculturelle à La Réunion où les conceptions traditionnelles de l'être, de la personne, du monde et du corps seraient à entendre, dans le respect de l'ancrage identitaire de nos patients et de leurs choix thérapeutiques. Il s'agit donc d'une contribution, dans le domaine psychologique, à l'essor du «pluralisme médical » (Penkala-Gawecka et Rajtar, 2016) à La Réunion.

\section{$\underline{\text { Bibliographie }}$}

Benoist, J. (2001). Santé, société et culture à la Réunion: anthropologie médicale et psychiatrie. Paris : Karthala.

Bonniol, J.-L. (2001). Introduction. (ed) Bonniol. Paradoxes du métissage. Paris : Éditions du Comité des travaux historiques et scientifiques. p. 7-23.

Bronstein, C (2016). Psychosomatique : le rôle du phantasme inconscient. Revue Française de Psychosomatique, n50. Nanterre : Presses Universitaires de France, p.117-132.

De Lame, D. (2007). Entre le dualisme et son double, les écueils de la construction de soi. Des difficultés d'analyse biopolitique en contexte postcolonial. Politique africaine, $\mathrm{n}^{\circ} 107$. Paris : Karthala. p. 9-22.

Donabédian, D. (2016). Du fantasme en psychosomatique. Revue Française de Psychosomatique, n50. Nanterre : Presses Universitaires de France, p.19-34.

Ghasarian, C. (2002). La Réunion : acculturation, créolisation et réinventions culturelles. Ethnologie française, vol. 32. Nanterre : Presses Universitaires de France. p. 663-676.

Govindama, Y. (2002). Culture et unité somato-psychique. Enfances \& Psy, n²0. Paris : Erès. p. 50-58.

Govindama, Y. (2011). Le monde hindou et l'Île de la Réunion. (ed) Govindama. Temps et rites de passage. Paris : Karthala. p. 41-61. 
Honoré, D. (2013). Diksionermoféknèt. Dictionnaire de propositions de néologismes créoles. Sainte-Clotilde : Surya Editions.

Honoré, D. (2002). Proverbes réunionnais. Saint-Denis : Editions UDIR.

Imiza, G. Bioy, A. (2010). Vécu psychique de la douleur et souffrance viscérale à l'île de la Réunion. Douleur et analgésie, n²3. Cachan : Lavoisier. p. 192-197.

Keller, P.-H. (2006). Le dialogue du corps et de l'esprit. Paris : Odile Jacob.

Penkala-Gawecka, D. Rajtar, M. (2016). Introduction to the special issue 'medical pluralism and beyond'. Anthropology \& Medicine, n²3. p.129-134.

http://dx.doi.org/10.1080/13648470.2016.1180584

Pourchez, L. (2002). La réinterprétation réunionnaise des apports de la biomédecine dans le domaine de la naissance et de la petite enfance. (ed) Jean Benoist. Santé, Société et Cultures à la Réunion. Paris : Karthala. p. 75-90.

Pourchez, L. (2005). Métissages à la Réunion : entre souillure et complexité culturelle. Africultures, $\mathrm{n}^{\circ}$ 62. Paris : L'Harmattan. p. 46-55.

Pourchez, L. (2010). Les problèmes de représentation de soi et de l'autre dans le contexte postcolonial réunionnais. (eds) Le Gall, D. Roinsart, N. Chroniques d'une autre France : La Réunion. Genres de vie et intimités créoles. Paris : L'Harmattan. p. 85-102.

Pourchez, L. (2014). Métissage, multi-appartenance, créolité à l'île de la Réunion. Anthropologie et sociétés, vol. 38, $\mathrm{n}^{\circ} 2$. Québec: Département d'Anthropologie de l’Université de Laval. p.45-66.

Smadja, C (2014). Le modèle pulsionnel de la psychosomatique. Revue Française de Psychosomatique, ${ }^{\circ}{ }^{45}$. Nanterre : Presses Universitaires de France. p.11-30.

Tarabout, G. (2012). Quelques conceptions de la personne et de l'ancestralité en Inde. (eds) Dreyfus-Aséo S., Tarabout G., Cupa D., Chaudoye G. Les ancêtres. Paris : EDK Editions. p. 53-61. 